\title{
Sezaryen Öncesi Açlık Süresinde Kanıta Dayalı Yaklaşım
}

\author{
Evidence Based Approach to Preoperative Fasting Time Before Cesarean Section
}

\author{
Tuba KIZILKAYA ${ }^{\mathrm{a}}$, Asiye GÜL ${ }^{\mathrm{b}}$
}

\begin{abstract}
ÖZ Kanıta dayalı uygulamalar klinikte hastalar için en doğru kararı vermede etkili olan uygulamaları içermektedir. Sezaryen öncesi hazırlık sürecinde açlık süresine ilişkin kılavuzlarda çeşitli öneriler ve kanıt düzeyleri mevcuttur. $\mathrm{Bu}$ süreçte eski bir uygulama olan nil per os (NPO) yani oral alımın gece yarısından itibaren kısıtlanması yaygın olarak uygulanır. Bu kısıtlamanın amacı aspirasyon ve regurjitasyon gibi anesteziye bağlı komplikasyonları en aza indirmektir. Cerrahi işlemin gecikmesi veya ertelenmesi açlık süresinin daha fazla uzamasına neden olur. Açlık süresinin uzaması ise dehidratasyon, insulin direnci, kaygı ve baş ağrısı gibi olumsuz sonuçlara yol açabilir. Bu olumsuz sonuçları en az düzeye indirmek için cerrahi öncesi açlıkla ilgili güncel kılavuzlar takip edilmelidir. Güncel kılavuzlarda sezaryen öncesi son iki saate kadar sıvı gıda alımına, son 6-8 saate kadar da katı gıda alımına izin verilmektedir. Ebeler başta olmak üzere sezaryen öncesi süreçte gebelere bakım veren sağlık profesyonelleri verilen bakımın kalitesini artırmak için güncel kılavuzları takip etmeli ve önerilere uygun girişimleri benimsemelidir. Bu derlemede sağlık profesyonellerinin konu ile ilgili bilgi düzeylerini arttırmak amaciyla sezaryen öncesi açlık süresinin etkileri, günümüzdeki uygulamalar ve öneriler ele alındı.
\end{abstract}

Anahtar kelimeler: açlık, ameliyat öncesi bakım, kanıta dayalı uygulama, sezaryen

\begin{abstract}
Evidence-based practices includes the best interventions for the patients. There are some evidences and suggestions about preoperative fasting time before cesarean section. Restricting oral intake of liquids or solids from midnight is an old practice called nil per os (NPO) is widely practiced in clinics. This is used to minimize the complications of anesthesia such as aspiration and regurgitation. When the surgical procedure delayed, fasting period is prolonged. Prolonged fasting times can cause harm effects like dehydration, insulin resistance, anxiety and headache. Current preoperative fasting guidelines and evidence-based practices should be followed to reduce these undesirable effects. Fasting from the intake of clear liquids for two hours; solids for six or eight hours before surgery is suggested in the current guidelines. Health professionals especially midwives who give care for women before cesarean section, should follow the current guidelines to increase the quality of healthcare. In this review, the effects of the pre-cesarean fasting period, current practices and recommendations were discussed in order to increase the knowledge level of health professionals.
\end{abstract}

Keywords: fasting, preoperative care, evidence-based practice, cesarean section

\section{Giriş}

Cerrahi işlem öncesi hazırlık; hastanın fizyolojik ve psikolojik olarak hazırlanması, premedikasyon uygulanması ve dinlenmenin sağlanması gibi temel unsurları içerir. ${ }^{1} \mathrm{Bu}$ süreçte en önemli konulardan biri de cerrahi işlem öncesi hastanın aç kalmasıdır. ${ }^{2}$ Günümüzde rutin bir uygulama olan cerrahi işlem öncesi oral alımın kısıtlanması literatürde "geceden itibaren aç kalma" anlamına gelen "Nil Per Os" (NPO) olarak da geçer. ${ }^{3} \mathrm{Bu}$ uygulamanın kökeni Mendelson'un 1940'larda yaptığı araştırmaya dayanır. Araştırmada genel anestezi altında sezaryen operasyonu geçiren 44016 kadının 66'sında aspirasyon gelişmiş, beşi aspirasyon nedeniyle hayatını kaybetmiştir. ${ }^{4}$
$\mathrm{Bu}$ araştırmanın sonucunda NPO, anestezi öncesinde rutin bir prosedür olarak uygulanmaya başlamıştır. Ancak güncel kılavuzlardaki bilgiler, cerrahi operasyon öncesi uzamış açlık süresinin olumsuz etkileri olduğunu, bu sürenin kısaltılmasının iyileşmeyi kolaylaştırdığı yönündedir. ${ }^{5}$ Çalışmalarda cerrahi öncesi açlık süresi ortalama 13,5-14 saat iken susuzluk süresi ortalama 11-12 saat arasında değişiklik göstermektedir. ${ }^{6,7,8}$ Klinikte uygulanan açlık süreleri kılavuz önerilerine kıyasla çok uzundur. Bu derlemede sağlık profesyonellerinin konu ile ilgili bilgi düzeylerini arttırmak amacıyla sezar-

Geliş Tarihi/Received:09-08-2017/ Kabul Tarihi/Accepted: 23-12-2017

a Arş. Gör. İstanbul Üniversitesi, Sağlık Bilimleri Fakültesi, Ebelik Bölümü, tuba.karaaslan44@gmail.com, ORCID: 0000-0003-3598-791X

b Doç. Dr. Sağlık Bilimleri Üniversitesi, Sağlık Bilimleri Fakültesi, Ebelik Bölümü, asiyegul2003@yahoo.com ORCID: 0000-0002-4440-5769

Sorumlu Yazar /Correspondence: Arş. Gör. Tuba Kızılkaya, İstanbul Üniversitesi, Sağlık Bilimleri Fakültesi, Ebelik Bölümü, tuba.karaaslan44@gmail.com

Araştırma "Sezaryen Öncesi Annenin Açlık Süresinin, Konfor ve Kaygı Düzeyinin Belirlenmesi” başlıklı yüksek lisans tezinin "Genel Bilgiler” bölümünden derlenmiştir. 
en öncesi açlık süresinin etkileri, günümüzdeki uygulamalar ve öneriler ele alındı.

\section{Pulmoner Aspirasyon Patofizyolojisi}

Aspirasyon riskinin en aza indirilmesi için aspirasyon mekanizmasının iyi anlaşılması gerekir. ${ }^{9,10}$ Bilincin kapalı olduğu veya larinksin koruyucu reflekslerinin baskılandığ 1 durumlarda, intragastrik basınç alt özofagus basıncını geçer. Aspirasyonun gelişmesi için öncelikle gastrik içerik alt özofajeyal sfinktere ulaşmalı ve ardından gastroözofajeyal reflü gerçekleşmelidir. Asidik materyal, özofagusun $30 \mathrm{~cm}$ gerisindedir ve regurjite olduğunda üst özofajeyal sfinkteri geçerek farinksi kontamine eder. Eğer hastanın bilinç düzeyi azaltılmışsa doğal olarak öksürme, aksırma ve yutma refleksleri baskılanır. Pasif regürjitasyon ve kusma ile mide içeriği akciğerlere ulaşır. ${ }^{11}$ Trakeo-bronşiyollere ulaşan gastrik içerik hayatı tehdit eden solunum sorunlarının oluşmasına neden olur. ${ }^{5,9,10}$

Preoperatif açlı süresinin uzaması, cerrahi işlemlerin vücutta yol açtığı katabolik süreci olumsuz yönde etkiler. Hastanın glikojen depolarının tükenmesiyle birlikte insülin direncinde de artış meydana gelir. ${ }^{12}$ Açlık süresinin uzamas1 ayn1 zamanda dehidratasyon, bulantı-kusma, hipovolemi, kaygı, baş ağrısı ve hipoglisemi gibi olumsuz sonuçlara yol açar. ${ }^{5,7}$ Özellikle hipoglisemi uzun açlık sürelerinden sonra en çok korkulan komplikasyonlardan biridir. ${ }^{13}$ Ayrıca, üriner ozmolaritenin yükselmesine ve dehidratasyona neden olabilmektedir. $^{14}$

\section{Aspirasyon İçin Risk Faktörleri}

Narkotik premedikasyon mide boşalmasını yavaşlatarak mide içeriğinin asitliğini ve hacmini arttırır. ${ }^{11}$ Anestezik ilaçlar; bilincin kapalı hale gelmesine, kasların gevşemesine ve geçici duyu kaybına yol açar., ${ }^{9,15}$ Mendelson'ın 1946 'da yayınladı̆̆ 1 çalışmasında sezaryen sirasinda aspirasyon riski \%0,15 olarak bulunmuştur. ${ }^{4}$ Günümüzde modern anestezi tekniklerinin uygulanması ve rejyonel anestezi kullanımının artması, Mendelson sendromunun ve genel anestezi sırasında regürjitasyonun görülme sıklığını azaltmaktadır. ${ }^{16}$ Anestezi sırasında aspirasyon riski, sezaryende çok düşük olsa da aspirasyonun ortaya çıkması durumunda morbidite ve mortalite riski yüksektir. ${ }^{17}$ Yapılan bir çalışmada, sezaryen surasında aspirasyon gelişme riski $\% 0,06$, buna bağlı maternal mortalite riskinin de $\% 0,001$ olduğu ifade edilmektedir. $^{18}$
Özofagus hastalığı (hiatus hernisi, özofajit, akalazya) ileus, mide çıkış darlığı, çok küçük ya da ileri yaş, acil cerrahi girişimler, nörolojik bozukluklar, şişmanlık, peptik ülser ya da gastrit öyküsü, geçirilmiş üst gastrointestinal cerrahi, aşırı kaygı, narkotik premedikasyon anestezi sırasında aspirasyon riskine yol açan faktörlerdendir. ${ }^{19}$ Gebelikte aspirasyon için risk faktörleri Tablo 1'de özetlenmiştir. ${ }^{10,11}$

Tablo 1. Gebelikte aspirasyon açısından risk faktörleri

Risk Faktörleri

Karın içi basıncın artması

Progesteronun etkisiyle alt özofajeyal

sfinkter tonusunun azalması

Gastrin hormonunun artması

Gastroözofajeyal reflünün artmas1

Plasentanın gastrik asit sekresyonunu

arttırmas1

Mide boşalmasının gecikmesi

\section{Kanıta Dayalı Uygulama}

Kanıta dayalı tıp, hasta bakımı ile ilgili kararlarda eldeki en iyi bilimsel kanıtın açık ve doğru bir şekilde kullanılmasını sağlamaya yönelik sistematik bir yaklaşım olarak tanımlanır. ${ }^{20}$ Kanita dayalı uygulamanın anlamı, sistematik araştırmalardan elde edilen en iyi kanıtların uygulama ile birleştirilerek kullanılmasidır. Kanita dayalı uygulamada, belli bir konuda araştırmalar seçilir, sonuçları sentezlenir ve kanıt değeri belirlenerek klinik uygulamada kullanılır. ${ }^{21}$ Bilimsel araştırmalarda kanıt düzeylerini belirleyen, tüm dünyada yaygın olarak kullanılan ülkemizde de Sağlık Bakanlığı'nın tanı, tedavi rehberinde yer alan Scottish Intercollegiate Guidelines Network (SIGN) sinıflaması kullanılmaktadır. ${ }^{22}$ SIGN siniflamasına göre kanıt düzeyleri ve öneriler Tablo 2'de gösterildi. ${ }^{23}$

\section{Sezaryen Öncesi Önerilen Açlık Süreleri ve Kanıt Düzeyleri}

Amerikan Anestezistler Derneği (American Society of Anesthesiologists-ASA) 1999 yilinda yayınladığı ve 2011 yılında güncellediği rehberde, cerrahi işlem öncesi açlik sürelerinin hafifletilmesine ilişkin önerilere yer vermektedir. ${ }^{23,24}$ ASA'nın önerileri aşağıda yer almaktadır;

- Yetişkin ve çocuklarda elektif operasyon öncesi (sezaryen dahil) son iki saate kadar 
berrak slvilar (su, posasız meyve suyu ve sütsüz çay veya kahve) içebilir (Kanıt seviyesi $1++$, öneri derecesi $A$ ).

$\mathrm{Su}$, meyve suyu, çay ve kahve gibi berrak sıvılar yaklaşı olarak bir saatte mideden boşalmaya bașlar, sıvının mideden tamamen uzaklașması ise iki saat sürer. ${ }^{25}$ Açlık süresiyle ilgili yayınlanan k1lavuzların incelendiği sistematik bir derlemede cerrahi öncesi son iki saate kadar berrak sıv1 alınabileceği ve çoğu hasta için aç kalmanın gereksiz olduğu A kanıt düzeyi olarak açıklanmıştır. ${ }^{26}$ Son yayınlanan obstetrik anesteziyle ilgili kılavuza göre elektif operasyon uygulanacak ve komplikasyon riski olmayan gebeler, son iki saate kadar berrak siv1 tüketebilmektedir. ${ }^{27}$ Tam bir öğün ise sekiz saat öncesinde yenilebilir. Bu öğün içinde et gibi sindirimi uzun süren besinler yer alır. ${ }^{24}$

\begin{tabular}{|c|c|}
\hline \multicolumn{2}{|c|}{ Kanıt Seviyesi } \\
\hline $1++$ & $\begin{array}{l}\text { Yüksek kalitede meta-analizler, randomize kontrollü deneylerin sistematik derlemeleri } \\
\text { veya çok düşük bias riski içeren randomize kontrollü deneyler }\end{array}$ \\
\hline $1+$ & $\begin{array}{l}\text { İyi uygulanmış meta-analizler, sistematik derlemeler veya düşük bias riski olan } \\
\text { randomize kontrollü deneyler }\end{array}$ \\
\hline $1-$ & $\begin{array}{l}\text { Meta-analizler, sistematik derlemeler veya yüksek bias riski olan randomize kontrollü } \\
\text { deneyler }\end{array}$ \\
\hline $2++$ & Vaka kontrol veya kohort çalışmalarının yüksek kalitedeki sistematik derlemeleri \\
\hline $2+$ & $\begin{array}{l}\text { İyi uygulanmış, düşük yanlılık veya çelişme riski düşük ve orta düzeyde nedensel ilişki } \\
\text { olasilığı içeren, vaka kontrol veya kohort araştırmaları }\end{array}$ \\
\hline $2-$ & $\begin{array}{l}\text { Yüksek yanlılık veya çelişme riski olan ve nedensel olmayan ilişki olasıllı̆ı içeren vaka } \\
\text { kontrol veya kohort araştırmaları }\end{array}$ \\
\hline 3 & Analitik olmayan çalışmalar, vaka raporları, vaka serileri \\
\hline 4 & Uzman görüşleri \\
\hline \multicolumn{2}{|c|}{ Öneri Derecesi } \\
\hline A & $\begin{array}{l}\text { 1++ düzeyinde en az bir meta-analiz, sistematik derleme veya randomize kontrollü } \\
\text { deneyler ve hedef topluma doğrudan uygulanabilir veya } 1+\text { düzeyinde çalışmalardan elde } \\
\text { edilmiş kanitların varlığ } 1 \text {, }\end{array}$ \\
\hline B & $\begin{array}{l}\text { Hedef topluma doğrudan uygulanabilirlik ve tüm sonuçların tutarlllığını gösteren } 2++ \\
\text { düzeyinde çalışmalardan elde edilmiş kanıtların varlığı, hedef topluma doğrudan } \\
\text { uygulanabilir ve tüm sonuçların tutarlılığının gösterimi veya } 1++ \text { ve } 1+\text { düzeyinde } \\
\text { çalışmalardan yapılan çıkarımlara dayalı kanıtlar }\end{array}$ \\
\hline $\mathrm{C}$ & $\begin{array}{l}\text { 2+ düzeyinde çalışmalardan elde edilmiş kanıt varlı̆̆ı, hedef topluma doğrudan } \\
\text { uygulanabilirlik ve tüm sonuçların tutarlılığının gösterimi veya } 2++ \text { düzeyinde } \\
\text { çalışmalardan yapılan çıkarımlara dayalı kanıtlar }\end{array}$ \\
\hline $\mathrm{D}$ & $\begin{array}{l}3 \text { ve } 4 \text { düzeyde kanıtlar veya } 2+\text { düzeyinde çalışmalardan yapılan çıkarımlara dayalı } \\
\text { kanıtlar }\end{array}$ \\
\hline
\end{tabular}

Katı besinler, sıvılara göre daha geç sindirilirken yağlı ve etli yemekler ise sekiz saat veya daha uzun sürede sindirilir. ${ }^{28}$ Türk Anesteziyoloji ve Reanimasyon Derneği'nin Obstetrik Anestezi Komitesi de genel anestezi altında sezaryen yapılacak hastalar için sekiz saat öncesinde katı gıda tüketilebileceğini, son iki saate kadar sadece berrak sıvı alınabileceğini belirtir. ${ }^{29}$
Büyük Britanya ve İrlanda Anestezistler Derneği ve Obstetrik Anestezistler Derneğinin yayınladığı ortak kılavuzda; planlı operasyon uygulanacak kadınların uzun süreli açlığa maruz kalmamaları ve ameliyattan iki saat öncesine kadar berrak sivı alımlarının desteklenmesi gerektiği belirtilmektedir. ${ }^{30}$ Kılavuzlarda önerilen yaklaşımların hastanın durumuna göre uyarlanabileceği bildirilmektedir. ${ }^{24}$ 
- Katı gıda, yetişkin ve çocuklarda elektif cerrahide alt saat öncesinde yasaklanmalıdır (Kantt seviyesi 1+, öneri derecesi A).

ASA altıncı saatten önceki katı besini hafif bir kahvaltı şeklinde tanımlamaktadır. ${ }^{24}$

- Obez, gastroözofajeyal reflü, diyabet ve doğum aşamasında olmayan hamile kadınlar elektif cerrahi öncesi iki saat öncesi berrak sivılar, altı saat öncesi katı gıdaları güvenle alabilir (Kantt seviyesi 2-, öneri derecesi $D$ ).

Kurban ve ark.'nın olgu sunumunda morbid obez olan ve şiddetli preeklempsi tanısı konulan gebede aspirasyon pnömonisi geliştiği bildirilmektedir. ${ }^{17}$ Doğum yapacak kadınlarda aspirasyon açısından risk faktörleri (diyabet, morbid obezite ve zor havayolu vb.) bulunması durumunda kişiye özel bir yol izlenmelidir. ${ }^{27}$ Süt gibi içecekler kesilip, katı hale gelebileceğinden katı gida grubunda yer alır. ${ }^{28}$

- Karbonhidrattan zengin sivilar elektif cerrahi öncesi diyabetik hastalar da dahil tüm hastalara iki saate kadar güvenle verilebilir (Kanıt seviyesi 1++, öneri derecesi A).

- Elektif cerrahi öncesi içilen karbonhidrattan zengin sivllar susuzluk ve açlığ azaltır, kişinin kendini iyi hissetmesini sağlar ve ameliyat sonrası insülin direncini azaltır (Kanit seviyesi 1++, öneri derecesi $A$ ).

Cerrahi operasyon öncesinde yüksek karbonhidrat içeren berrak içeceklerin tüketilmesi daha az açlık ve susuzluğa yol açarak hasta konforunu yükseltmektedir ${ }^{12,31}$

- Normal doğum strasinda kadinlara isteklerine göre yukarıda belirtilen slvıları içmesine izin verilmelidir (Kant seviyesi 1++, öneri derecesi A). Aktif doğum strasinda katı gıda verilmemelidir (Kanit seviyesi 1+, öneri derecesi $A$ ).

- Hamile kadinlar, obez bireyler de dahil, cerrahiden (rejyonel veya genel anestezi) iki saat öncesine kadar berrak sivllarl tüketebilirler (Kanit seviyesi 1+, öneri derecesi A).

- $\mathrm{H}_{2}$ reseptör antagonisti, elektif sezaryen öncesinde sabah veya bir gün önce akşam verilmelidir (Kanit seviyesi 1++, A).
Intravenöz $\mathrm{H}_{2}$ reseptör antagonisti acil sezaryenden önce verilmelidir (Kanıt düzeyi 1++, Öneri derecesi A). ${ }^{23}$

Sezaryen ve diğer cerrahi girişimlerin öncesinde, açlık süresinin azaltılması ile ilgili literatürde çeşitli çalışmalar yer alsa da günümüzde NPO yaygın şekilde uygulanmaktadır. ${ }^{32}$

\section{Sonuc}

Ameliyat öncesi açlık ile ilgili kılavuzlar; kanıta dayalı uygulamaları ve uzmanlar tarafindan kabul gören genel yaklaşımları sağlık profesyonellerine aktarmay1 hedefler. Komplikasyonların ortaya çımaması ve sorunların azaltılması için kanıta dayalı uygulamalar benimsenmelidir. $\mathrm{Bu}$ nedenle sezaryen öncesinde aspirasyon açısından risk faktörleri kişiye özel şekilde ele alınmalı ve açlık süresi buna göre düzenlenmelidir. Güncel yaklaşımların yer aldığı kılavuzlar doğrultusunda, gebenin klinik durumu da göz önünde bulundurularak, sezaryen öncesi açlık süresinin azaltılmasının gebenin sezaryen sonrası iyileşme sürecine de olumlu yansıyacağı düşünülmektedir.

\section{Kaynaklar}

1. Chard R. Care of preoperative patients. In: Ignatavicius DD, Workman ML, eds. Medical-Surgical Nursing: Patient-Centered Collaborative Care, 7 th ed. St. Louis: Saunders Elsevier; 2013. p:239-254.

2. WHO Guidelines for safe surgery: Safe surgery saves lives 2009. (Cited: 25.07.2017) Available from: http://apps.who.int/iris/bitstream/10665/441 85/1/9789241598552 eng.pdf

3. Ljungqvist O. Preoperative fasting and carbohydrate treatment. In: Feldman LS, Delaney CP, Ljungqvist O, Carli F, editors. The SAGES / ERAS ${ }^{\circledR}$ society manual of enhanced recovery programs for gastrointestinal surgery. Switzerland: Springer International Publishing; 2015. p.41.

4. Mendelson CL. The aspiration of stomach contents into the lungs during obstetric anesthesia. Obstetrical \& Gynecological Survey 1946; 1(6), 837-839.

5. Demirdağ H \& Karaöz S. Ameliyat öncesi besin/sıv1 kısıtlamasına ilișkin hastaların deneyimleri ve hemşirelerin konu ile ilgili bilgi ve uygulamaları [Patients experiences about preoperative fasting and nurses knowledge and practice] Florence 
Nightingale Hemşirelik Dergisi [Florence Nightingale Journal of Nursing] 2015; 23(1), $1-10$.

6. Dolgun E, Taşdemir N, Ter N, \& Yavuz M. Cerrahi hastalarının ameliyat öncesi aç kalma sürelerinin incelenmesi [Investigation of preoperative fasting times of surgical patients]. Fırat Üniversitesi Sağlık Bilimleri Tıp Dergisi [Frrat University Journal of Health Sciences Medicine] Dergisi 2011; 25 (1): $11-15$

7. Gül A, Andsoy II, Üstündağ H, Özkaya BÖ. Assessment of preoperative fasting time in elective general surgery. The Journal of Macro Trends in Health and Medicine 2013; 1(1): 1-8.

8. Robson EJ., Tanqueray TA, Mackenzie MJ \& Yentis SM. The effect of reducing fluid fasting times on thirst and urine osmolality in women undergoing elective caesarean delivery. International Journal of Obstetric Anesthesia, 2013; 22(2), 165-167.

9. Jolliffe DM. Practical gastric physiology. Continuing education in anaesthesia, Critical Care \& Pain, 2009; 9(6), 173-177.

10.Tasch MD and Langeron O. In: Hagberg CA, ed. Aspiration prevention and prophylaxis: preoperative considerations. Benumof And Hagberg's Airway Management, 3rd edition, Philadelphia: Elsevier Saunders; 2013. pp:265-268

11. Yıldız H. Preoperatif açlık sürecinde yeni yaklaşımlar. [New approaches during preoperative poverty process] AÜTD [MJAU] 2006; 38, 1-5.

12. Canbay Ö, Adar S, Karagöz AH, Çelebi N, \& Bilen CY. Effect of preoperative consumption of high carbohydrate drink (Pre-Op $\left.{ }^{\circledR}\right)$ on postoperative metabolic stress reaction in patients undergoing radical prostatectomy. International Urology and Nephrology 2014; 46(7), 1329-1333.

13.Tauhid-Ul-Mulk M, Rahman SMF, Ali NP, Haque M \& Chaudhary MRA. Influence of preoperative fasting time on maternal and neonatal blood glucose level in elective caesarean section under subarachnoid block. Journal of Armed Forces Medical College 2010; 6(2), 21-24.

14.Mackenzie M, Yentis S, Woolnough $M$ and Johnson M. Fasting periods and dehydration before elective caesarean section. Anaesthesia, 2010; 65, 94-113.

15.Brady MC, Kinn S, Stuart P, Ness V. Preoperative fasting for adults to prevent perioperative complications. Cochrane Database of Systematic Reviews. 2010; Issue 4. Art. No.: CD004423

16.Singata M, Tranmer J, Gyte GML. Restricting oral fluid and food intake during labour. Cochrane Database of Systematic Reviews 2013; 8. Art.No.:CD003930.

17.Kurban Y, Uyar İ, Günakan E, \& Babayiğit M. Demonstratif bir sezaryen komplikasyonu ve yönetimi: aspirasyon pnömonisi [A demonstrative cesarean complication and management: aspiration pnomonia] Tepecik Eğit Hast Derg [The Journal of Tepecik Education and Research Hospital] 2014; 24 (2): $147-150$

18.Lesage S. Cesarean delivery under general anesthesia: Continuing Professional Development. Canadian Journal of Anesthesia/Journal Canadien d'anesthésie, 2014; 61(5), 489-503.

19.Ersoy E \& Gündoğdu H. Preoperatif açlikta değişen kavramlar [Alternating concepts in preoperative fasting]. Ulusal Cerrahi Dergisi [Turkish Journal of Surgery] Ulusal Cerrahi Dergisi 2005; 21(2), 096-101.

20.Yılmaz E \& Çöl M. Kanıta dayalı tıp [Evidence based medicine]. Journal of Clinical and Analytical Medicine 2014; 5(6):537-542

21.Kocaman G. Hemşirelikte kanıta dayalı uygulama [Evidence-based practice in nursing]. Hemşirelikte Araştırma Geliştirme Dergisi 2003; 2:61-69.

22.Açıkel C. Meta-analiz ve kanıta dayalı Tip'taki yeri [Meta-analysis and its place in evidence based medicine]. Bulletin of Clinical Psychopharmacology, 2009; 19:164172.

23.Smith I, Kranke P, Murat I, Smith A, O'Sullivan G, Søreide E, Spies C, Bas in't Veld B. Perioperative fasting in adults and children: guidelines from the European Society of Anaesthesiology. Eur $\mathbf{J}$ Anaesthesiol, 2011; 28:556-569.

24.American Society of Anesthesiologists Committee (ASA). Practice guidelines for preoperative fasting and the use of pharmacologic agents to reduce the risk of pulmonary aspiration: application to healthy patients undergoing elective procedures: an updated report by the American Society of Anesthesiologists Committee on Standards and Practice Parameters. Anesthesiology, 2011;114(3), 495. 
25.Levy DM. Pre-operative fasting-60 years on from Mendelson. Continuing Education In Anaesthesia, Critical Care \& Pain 2006; 6(6), 215-218.

26.Lambert E. \& Carey S. (2015). Practice guideline recommendations on perioperative fasting a systematic review. Journal Of Parenteral And Enteral Nutrition, 20(10): 18.

27.American Society of Anesthesiologists Task Force on Obstetric Anesthesia. (2016). Practice guidelines for obstetric anesthesia: an updated report by the American Society of Anesthesiologists Task Force on Obstetric Anesthesia. Anesthesiology 2016; 2(124): 270-300.

28. Sandhar B. General considerations. In K. G. Allman, \& I. H. Wilson (Eds.), Oxford Handbook of Anaesthesia, 3rd edition, New York: Oxford university press; 2011. p:10

29.TARD- Türk Anesteziyoloji ve Reanimasyon Derneği [Turkish Society of Anesthesiology and Reanimation] Sezaryen Ameliyatlarında Genel Anestezi Uygulama Kılavuzu 2015. http://www.tard.org.tr/assets/kilavuz/9.pdf (Son erişim tarihi:25.07.2017)

30.The Association of Anaesthetists of Great Britain \& Ireland and the Obstetric Anaesthetists' Association (2013). https://www.aagbi.org/sites/default/files/obst etric_anaesthetic_services_2013.pdf (Son erişim tarihi:25.07.2017)

31.Imbelloni LE. Pombo IAN \& Morais Filho GBD. Reduced fasting time improves comfort and satisfaction of elderly patients undergoing anesthesia for hip fracture. Revista Brasileira De Anestesiologia, 2015; 65(2), 117-123.

32. Crenshaw JT. Preoperative fasting: will the evidence ever be put into practice. The American Journal of Nursing, 2011; (10), 3843. 